\title{
Assessment of the Level of Knowledge, Attitude, and Practice with Regard to Care of People Living with HIV/AIDS among Nursing and Midwifery Students in Fako, Cameroon
}

\author{
Delphine Mbong Wam Iwoi' ${ }^{1}$ Peter Fon Nde ${ }^{1,2}$, Euphrasia Yuh ${ }^{3}$, Emmanuel Tebit Kwenti2,4*, \\ Edouard Katayi Tshimwanga ${ }^{5}$, Denis Tange Achiri ${ }^{6}$, Kenne Emmanuel Djunda7
}

${ }^{1}$ Department of Nursing, Faculty of Health Sciences, University of Buea, Buea, Cameroon

${ }^{2}$ Department of Public Health and Hygiene, Faculty of Health Sciences, University of Buea, Buea, Cameroon

${ }^{3}$ Department of Educational Psychology, Faculty of Education, University of Buea, Buea, Cameroon

${ }^{4}$ Department of Medical Laboratory Sciences, Faculty of Health Sciences, University of Buea, Buea, Cameroon

${ }^{5}$ AIDS Control Program, Cameroon Baptist Convention Health Services Complex, Mutengene, Cameroon

${ }^{6}$ Institute of Applied and Natural Science, Cukurova University, Adana, Turkey

${ }^{7}$ Department of Anaesthesia, University of Calabar Teaching Hospital, Calabar, Nigeria

Email: *kwentitebit@yahoo.com, *emmakwen@gmail.com

How to cite this paper: Iwoi, D.M.W. Nde, P.F., Yuh, E., Kwenti, E.T., Tshimwanga, E.K., Achiri, D.T. and Djunda, K.E. (2017) Assessment of the Level of Knowledge, Attitude, and Practice with Regard to Care of People Living with HIV/AIDS among Nursing and Midwifery Students in Fako, Cameroon. World Journal of AIDS, 7, 1-15.

https://doi.org/10.4236/wja.2017.71001

Received: December 5, 2016

Accepted: January 13, 2017

Published: January 16, 2017

Copyright $\odot 2017$ by authors and Scientific Research Publishing Inc. This work is licensed under the Creative Commons Attribution International License (CC BY 4.0).

http://creativecommons.org/licenses/by/4.0/

c) (7) Open Access

\begin{abstract}
Due to the chronic shortage of health personnel, nurses and midwives now play a fundamental role in the care and treatment of people living with HIV/ AIDS (PLHIV) in Cameroon. This study was therefore designed to assess the level of knowledge, attitude and practice with regard to care of PLHIV among nursing and midwifery students in Fako division of Cameroon. A survey was performed between May and July 2015, among 227 nursing and midwifery students (in their second to final year of study), selected from 8 government accredited training institutions in Fako division of Cameroon. An anonymous self-administered semi-structured questionnaire was used to collect data. The Pearson's chi-square test, univariate and multivariate logistic regression analyses adjusting for possible confounders were all performed as part of the statistical analyses. The cutoff of statistical significance was set at $p \leq 0.05$. Nursing and midwifery students had a moderate level of HIV/AIDS knowledge (average score of 7.02 on a scale of 11). Attitude towards PLHIV was generally positive $(68.7 \%)$ but there were some misconceptions and prejudice about PLHIV, with considerable stigmatization (31.3\%), unwillingness to share a room with someone infected with HIV (27.7\%), and unwillingness to work on PLHIV (23.8\%). Good HIV/AIDS knowledge was observed to be the sole independent predictor $(\mathrm{p}=0.004)$ of positive attitude towards PLHIV. Fur-
\end{abstract}


thermore the confidence of the respondents regarding care of PLHIV was generally moderate. Our results suggest the need for the development of a more appropriate education program in nursing and midwifery institutions in Fako division to reduce the discrepancies between the general knowledge, attitude and practice regarding care of PLHIV.

\section{Keywords}

Knowledge, Attitude, Practice, People Living with HIV/AIDS, Nursing, Midwifery, Students, Fako Division, Cameroon

\section{Introduction}

Human Immunodeficiency Virus (HIV) is one of the most important infectious diseases in the world today. Globally, there were an estimated 36.7 million people living with HIV/AIDS (PLHIV) in 2015 [1]. Sub-Saharan Africa has the highest burden of HIV with an estimated 23.5 million PLHIV [2], while Cameroon has the highest burden of HIV in West and Central Africa (WCA), with an estimated 620,000 PLHIV, projected to increase to 726,000 by 2020 [3] [4] [5]. With the rising number of PLHIV in the country, there is an intense pressure on the health infrastructure to care for these patients.

Unfortunately, there is an acute shortage of health personnel in Cameroon with ratios of 2 doctors and 16 nurses for every 10,000 patients [6]. Considering the workload on the available human resources, the World Health Organization (WHO) recommends tasks shifting from doctors to nurses, midwives and other non-clinicians staff in the management of HIV and AIDS [7]. In Cameroon task shifting has become a common practice along the care and treatment cascade in most HIV/AIDS treatment facilities. Consequently nurses and midwives are expected to perform HIV counselling and testing, clinical assessment, initiation and monitoring of antiretroviral therapy in addition to adherence and psychosocial assessment and support along the continuum of care [7]. Nurses and midwives are also involved in primary data collection, record keeping and reporting which makes monitoring and evaluation of services feasible, guide decision making and ensure the provision of quality services [7].

As nurses and midwives are fast becoming the key player in the care of PLHIV, they must first be adequately trained [8]. Different reports have revealed that nurses lack adequate knowledge, skills and demonstrate poor attitude towards PLHIV because they are not well trained during their pre-service education [9]-[14]. For example, the study by Ajobiewe and Uwakwe [10] revealed that nursing and midwifery students had a poor knowledge of the WHO recommended universal precautions for preventing HIV transmission. The study also revealed that midwifery students performed more high risk occupational practices compared to nursing students but received less supervision [10].

Nursing and midwifery students' knowledge on the care of PLHIV is therefore 
of vital importance since they are the future practicing nurses and midwives. Studies assessing the education of nursing and midwifery students are limited in Cameroon. This study was designed to assess the knowledge, attitude, and practice with regard to care of PLHIV among nursing and midwifery students from training facilities in Fako division of Cameroon. Data from this study will contribute towards the improvement of the training of nursing and midwifery students in Cameroon.

\section{Materials and Methods}

\subsection{Study Design, Duration and Setting}

A survey was performed using a cross section of regular undergraduate nursing and midwifery students selected from government accredited training institutions of Cameroon between May and July 2015.

The study was conducted in Fako Division $\left(4^{\circ} 10^{\prime} 00^{\prime \prime} \mathrm{N}, 9^{\circ} 10^{\prime} 00^{\prime \prime} \mathrm{E}\right)$ in the South West region of Cameroon. The estimated HIV prevalence in Fako is $10.7 \%$ in the general population [15], making it one of the highest in the region. There are 8 nursing and midwifery Institutions in Fako and all were included in the study: Redemption Medical Foundation (RMF), Muyuka; Maflekumen Higher Institute of Health Sciences, Tiko; St. Francis School of Health Sciences (SFSHS), Buea; St. Jude Higher Institute of Health Sciences, Buea; Training School for Health Personnel, State Registered Nursing (TSHP-SRN), Limbe; St. Monica University, Muea; Department of Nursing, Faculty of Health Sciences (FHS), University of Buea, Buea; Higher Institute of Applied Medical Sciences (HIAMS), Buea. Altogether, 552 regular undergraduate nursing and midwifery students were registered in these training institutions during the study timeframe.

\subsection{Sample Size Estimation}

The sample size was estimated using the online tool Raosoft $\mathrm{f}^{\circledR}$ sample size calculator [16]. Using a margin of error of 5\%, confidence level of $95 \%$, population size of 552 and response distribution of 50\%, the estimated sample size was 227 .

\subsection{Study Population}

Regular undergraduate nursing/midwifery students in the training institutions listed above were targeted. A stratified cluster sampling technique was used to recruit participants from the different levels in the different Institutions. The total number of participants recruited was proportional to the number of students enrolled at the different levels in the different institutions. To be included into the study, the participants were to be either male or female, aged 17 years and above, and at the first year of training (level 2) and above.

\subsection{Ethical Consideration}

Ethical approval for the study was obtained from the Faculty of Health Sciences Institutional Review Board (FHS IRB) of the University of Buea, Cameroon. 
Administrative clearance was obtained from the Delegation of Public Health, South West Region (SWR) of Cameroon, as well as from the administration of the different nursing and midwifery institution. Written informed consent was obtained from all participants.

\subsection{Data Collection}

An anonymous self-administered semi-structural questionnaire was used for data collection. The questionnaire used in this survey was based on the WHO AIDS program regarding knowledge, attitudes, beliefs and practices (KABP) in 1988 [17], as well as other related literatures for health workers evaluation of self-confidence. Internal reliability of the questionnaire was established by a Cronbach's alpha of 0.90 and the content viability was established by using a second measure of research utilization and feedback from experts in the field.

The questionnaire was divided into five parts, the first part obtained demographic and personal data, years in nursing/midwifery school, and years of experience and work setting (internships). The second part obtained information on student's knowledge about HIV/AIDS prevalence, vulnerable group, transmission, treatment and control. The third part obtained information about student's attitudes towards HIV/AIDS patients and the student's quest for more information about HIV/AIDS. The fourth part of this questionnaire sort to know and evaluate the common beliefs students hold about the disease conditions and the way forward, and the last part evaluates the student's practices towards HIV/ AIDS patients and their willingness and motivation to improve practices to boost their self-efficacy.

Responses to most items concerning practice, knowledge, and skills related to self-efficacy was addressed using a 5-point Likert scale with "None/not at all" and "very high" as anchors. Several items related to access to information, required a dichotomous response "yes/no".

The questionnaire was pretested on a sample of 20 students selected from the Faculty of Science of the University of Buea. Printed copies of the questionnaire were handed to the respondents in person. To ensure confidentiality, no name was collected, instead codes were used to identify the respondents. Furthermore, the respondents were also provided with an envelope to seal the questionnaire upon completion before submission.

\subsection{Assessment of Knowledge on HIV/AIDS}

There were 11 indicators used to evaluate the knowledge of respondents. Knowledge was scored on 11, one for each indicator. Respondents who score below 5 were considered as having poor knowledge on HIV/AIDS, scores between 5 and 9 as having moderate knowledge on HIV/AIDS, and scores above 10 as having good knowledge on HIV/AIDS.

\subsection{Assessment of Attitude towards HIV/AIDS}

There were 7 indicators used to evaluate the attitude of the respondents. Attitude 
was scored on 7 , one for each indicator. Respondents who scored $\leq 4$ were considered as having a negative attitude towards PLHIV, and respondents who scored above 4 were considered as having a positive attitude.

\subsection{Statistical Analysis}

Data collected was entered into Excel spreadsheet and analysed using the SPSS version 16 for Microsoft windows. Frequency distributions of all relevant variables were presented in tables. Statistical analyses performed included the Pearson's chi-square test for group comparison, univariate and multivariate logistic regression adjusting for confounders, for the identification of predictors associated with positive attitude towards PLHIV.

\section{Results}

\subsection{Socio-Demographic Characteristics of the Respondents}

Table 1 shows the socio-demographic variables of the respondents. 227 regular undergraduate students participated in the survey, of whom 193 (85.0\%) were females and 34 (15.0\%) were males. A majority of the students 94 (40.9\%) were from the St. Francis School of Midwifery and Nursing Sciences. A vast majority of the respondents were nursing students 199 (87.7\%). Students from level 2 and level 3 constituted the bulk of the participants.

Table 1. Socio-demographic characteristics of the 227 respondents.

\begin{tabular}{|c|c|c|}
\hline Variables & Frequency & Percentage (\%) \\
\hline \multicolumn{3}{|l|}{ Gender } \\
\hline Male & 34 & 15.0 \\
\hline Female & 193 & 85.0 \\
\hline \multicolumn{3}{|l|}{ Institution } \\
\hline St. Monica & 13 & 5.7 \\
\hline St. Jude & 12 & 5.2 \\
\hline HIAMS & 31 & 13.5 \\
\hline University of Buea & 25 & 10.9 \\
\hline Maflekumen & 14 & 6.1 \\
\hline SRNS Limbe & 21 & 9.1 \\
\hline Redemption Muyuka & 17 & 7.4 \\
\hline St. Francis School & 94 & 40.9 \\
\hline \multicolumn{3}{|l|}{ Specialisation } \\
\hline Nursing & 199 & 87.7 \\
\hline Midwifery & 28 & 12.3 \\
\hline \multicolumn{3}{|l|}{ Level } \\
\hline 2 & 90 & 39.7 \\
\hline 3 & 78 & 34.4 \\
\hline 4 & 27 & 11.9 \\
\hline 5 & 32 & 14.1 \\
\hline \multicolumn{3}{|l|}{ Age (years) } \\
\hline Mean $=24.61( \pm 2.94)$ & Range 17 - 34 & \\
\hline
\end{tabular}

HIAMS: Higher Institute of Applied Medical Sciences, SRNS: State Registered Nursing School. 


\subsection{Knowledge about HIV/AIDS}

Table 2 shows the different indicators that were used to assess the knowledge on HIV/AIDS among the respondents. Nearly 8 in 10 (77.1\%) of the respondents did not know the correct meaning of HIV/AIDS. But almost all (99.6\%) the respondents knew that HIV was caused by a virus. Nearly three-quarter $(74.4 \%)$ of the respondents knew that HIV was more prevalent in women compared to men. Approximately two-third (66.5\%) of the respondents were aware that HIV can also be transmitted through the placenta. Meanwhile a few (3.1\%) of the respondents held the erroneous view that HIV can be transmitted via insect bite. Nearly 8 in $10(81.5 \%)$ of the respondents were aware that HIV could be deadly if not controlled. A great majority (96.9\%) of the respondents were aware that HIV is transmitted via unprotected sex with an infected person. Furthermore, nearly 9 in 10 (89.0\%) of the respondents knew that HIV can be transmitted by the use of unsterilized utensils.

Table 2. Knowledge on HIV/AIDS among the 227 respondents.

\begin{tabular}{|c|c|c|c|}
\hline Knowledge indicators & Response & Frequency & $\%$ \\
\hline \multirow[b]{2}{*}{ Meaning of HIV/AIDS } & Correct & 52 & 22.9 \\
\hline & Wrong & 175 & 77.1 \\
\hline \multirow{2}{*}{ HIV/AIDS is caused by a virus } & Correct & 226 & 99.6 \\
\hline & Wrong & 1 & 0.4 \\
\hline \multirow[b]{2}{*}{ HIV is more prevalent in women than men } & Correct & 169 & 74.4 \\
\hline & Wrong & 58 & 25.6 \\
\hline \multirow{2}{*}{ HIV can be transmitted via the placenta } & Correct & 151 & 66.5 \\
\hline & Wrong & 76 & 33.5 \\
\hline \multirow{2}{*}{ HIV can be transmitted via insect bite } & Correct & 220 & 96.9 \\
\hline & Wrong & 7 & 3.1 \\
\hline \multirow{2}{*}{ HIV is a deadly disease if uncontrolled } & Correct & 185 & 81.5 \\
\hline & Wrong & 42 & 18.5 \\
\hline \multirow{2}{*}{$\begin{array}{l}\text { HIV is transmitted via unprotected sex with an } \\
\text { infected person }\end{array}$} & Correct & 220 & 96.9 \\
\hline & Wrong & 7 & 3.1 \\
\hline \multirow{2}{*}{ HIV is transmitted by use of unsterilized utensils } & Correct & 202 & 89 \\
\hline & Wrong & 25 & 11 \\
\hline \multirow{2}{*}{ Symptoms of HIV/AIDS } & Correct & 222 & 97.8 \\
\hline & Wrong & 5 & 2.2 \\
\hline \multirow{2}{*}{ Knew how HIV could be diagnosed } & Correct & 202 & 89 \\
\hline & Wrong & 25 & 11 \\
\hline \multirow{2}{*}{ HIV can be treated with antiretroviral drugs } & Correct & 98 & 43.2 \\
\hline & Wrong & 129 & 56.8 \\
\hline
\end{tabular}


Overall, just a modest $33(14.5 \%)$ of the respondents had good HIV/AIDS knowledge, a majority 187 (82.4\%) of the respondents had moderate HIV/AIDS knowledge meanwhile a few 7 (3.1\%) of the respondents had poor HIV/AIDS knowledge. The average $( \pm \mathrm{SD})$ HIV/AIDS knowledge score was $7.02 \pm 1.73$. HIV/AIDS knowledge was not observed to be associated with the institution ( $\mathrm{p}$ $=0.783)$ or the level of study $(\mathrm{p}=0.085)$ or the age of the respondent $(\mathrm{p}=0.809)$ or the Specialisation $(\mathrm{p}=0.133)$ or the gender $(\mathrm{p}=0.427)($ Table 3$)$.

\subsection{Respondents' Self-Assessment of HIV Knowledge}

Respondents were asked to rate their knowledge of HIV. The responses were scored using a 5 - point Likert scale with "Not at all" and "Very high" as anchor. One (0.4\%) of the respondents reported to have no knowledge at all about HIV,

Table 3. The association of socio-demographic characteristics and knowledge of nursing students towards care of PLHIV.

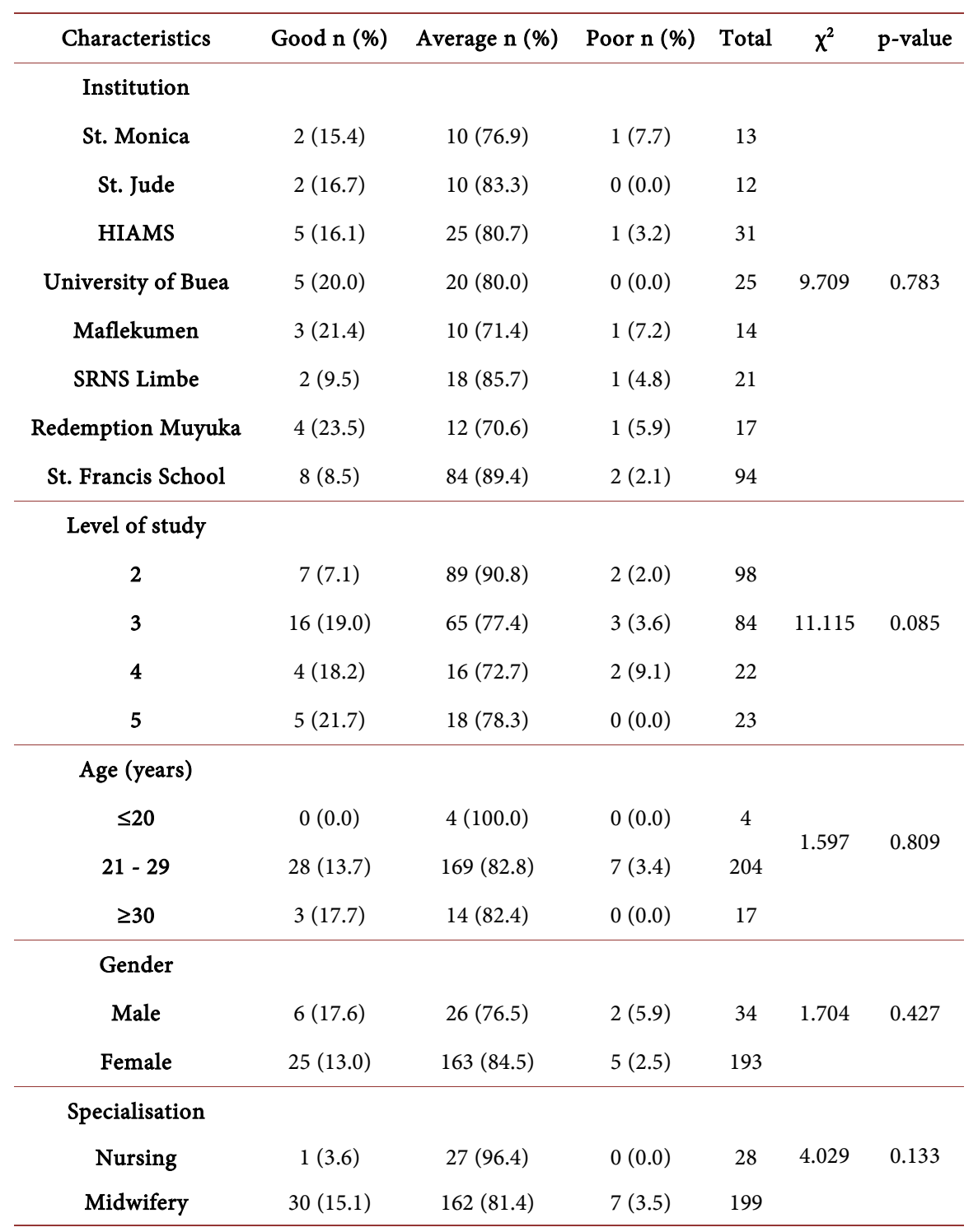

HIAMS: Higher Institute of Applied Medical Sciences, SRNS: State Registered Nursing School. 
meanwhile 27 (11.9\%) scored Very high. However, the majority of them scored Medium 94 (41.4\%) to High 105 (46.3\%).

\subsection{Attitude towards HIV/AIDS}

Table 4 shows the different attitude indicators used to evaluate the respondents. Among the participants who had had a friend or a relative who was HIV-positive, $27(18.2 \%)$ reported that their relationship was negatively affected. Approximately 3 in 10 (31.3\%) of the respondents accepted showing some form of stigmatization to PLHIV. Nearly 3 in 10 (27.7\%) were not willing to share their room with someone infected with HIV. Moreover, nearly one-quarter $(23.8 \%)$ of

Table 4. Attitude of the 227 respondents towards PLHIV and their willingness and motivation to work on PLHIV.

\begin{tabular}{|c|c|c|c|}
\hline Attitude indicators & Response & Frequency & $\%$ \\
\hline \multirow{2}{*}{ Relationship with HIV positive relative or friend affected negatively } & Yes & 27 & 18.2 \\
\hline & No & 121 & 81.8 \\
\hline \multirow{2}{*}{ Have stigma for PLHIV } & Yes & 65 & 31.3 \\
\hline & No & 143 & 68.8 \\
\hline Willing to work on PLHIV & No & 39 & 23.8 \\
\hline \multirow{2}{*}{ Should PLWHIV be isolated from mainstream society? } & Yes & 11 & 4.8 \\
\hline & No & 216 & 95.2 \\
\hline \multirow{2}{*}{ A cure for HIV is possible } & Yes & 162 & 71.3 \\
\hline & No & 65 & 28.7 \\
\hline Read extra literature on HIV/AIDS & No & 49 & 21.6 \\
\hline \multirow{2}{*}{ Share the same room with someone infected with HIV } & Yes & 164 & 72.3 \\
\hline & No & 63 & 27.7 \\
\hline \multirow{7}{*}{ Reasons for not willing to work on PLHIV } & Fear & 19 & 48.7 \\
\hline & Too demanding & 6 & 15.4 \\
\hline & Poor patient behaviour & 5 & 12.8 \\
\hline & Lack of interest & 2 & 5.1 \\
\hline & Emotional reasons & 1 & 2.6 \\
\hline & Lack of resources & 1 & 2.6 \\
\hline & Lack of training & 1 & 2.6 \\
\hline \multirow{10}{*}{ Motivating factors to work on PLHIV } & Training on HIV Care & 61 & 27 \\
\hline & Counselling on HIV care & 53 & 23.5 \\
\hline & Further training & 31 & 13.8 \\
\hline & Adequate equipment & 21 & 9.1 \\
\hline & Good patient behaviour & 8 & 3.6 \\
\hline & High wages & 7 & 3 \\
\hline & Personal satisfaction & 6 & 2.6 \\
\hline & Promote health & 1 & 0.4 \\
\hline & Reduced stigma & 1 & 0.4 \\
\hline & recruitment & 1 & 0.4 \\
\hline
\end{tabular}


the respondents were not willing to work on PLHIV. The main reasons put forth by the respondents for not willing to work on PLHIV were fear (48.7\%), the demanding nature of the work (15.4\%), poor patient behaviour (12.8\%) etc. (Table 4). The respondents advanced the following factors as their main motivation for them to work on PLHIV: care of nurses and midwives (27\%), counseling (23.5\%), more training (13.8\%) etc. (Table 4$)$. One hundred and eighty (78.3\%) reported to have read extra literature on HIV/AIDS. Overall. A majority of the respondents 156 (68.7\%) had positive attitude towards PLHIV meanwhile 71 (31.3\%) had a negative attitude. Good knowledge was the only independent predictor ( $\mathrm{p}$ $=0.004$ ) of positive attitude towards PLHIV adjusting for gender, age, level of study, specialisation and institution (Table 5).

Table 5. The predictors of positive attitude towards PLHIV among the 227 respondents.

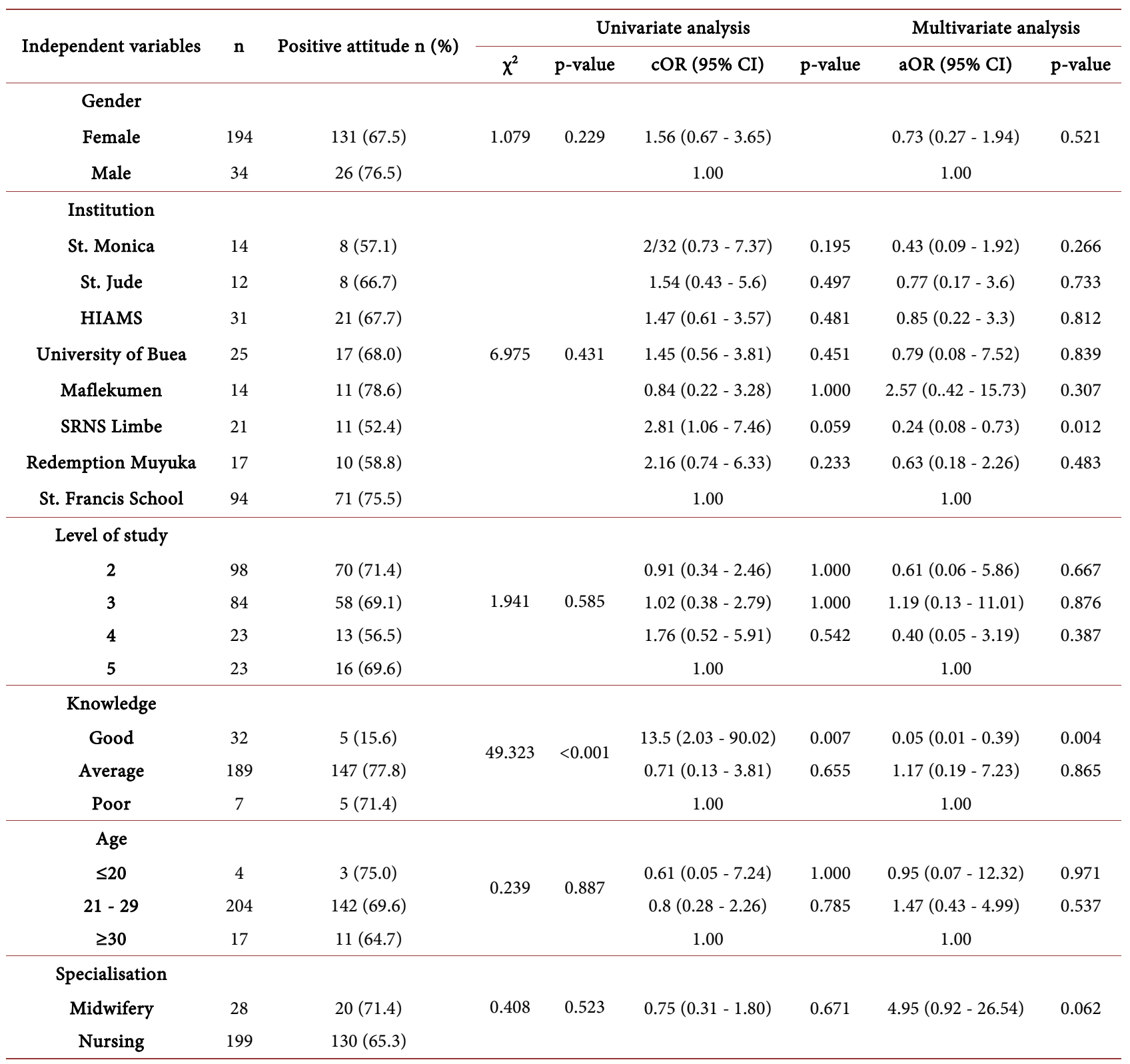

cOR: crude odd ratio; aOR: adjusted odd ratio, HIAMS: Higher Institute of Applied Medical Sciences, SRNS: State Registered Nursing School. 


\subsection{Practice towards Care of PLHIV}

A majority 217 (95.6\%) of the respondents had been an intern in a medical facility that receives PLHIV. The student interns were involved in various activities: administer drugs (28.3\%), care of PLHIV (17.8\%), and counseling (22.6\%). Among the respondents, only 56 (25.7\%) had used the WHO guidelines for classifying HIV/AIDS patients. The respondents who had been interns in a medical facility were asked to rate their confidence level of some HIV/AIDS healthcare delivery practices on a 5-point likert scale with "Not at all" and "Very High" as anchor (Table 6). Almost half of the respondents were not comfortable with changing the patients' medication (49.3\%) or the patients' dose (48.5\%). On the contrary, the confidence of the majority of respondents in counselling PLHIV was high $(30.4 \%)$ to very high $(31.3 \%)$. Furthermore, the majority of respondents were very cautious not to get infected when taking care of HIV/AIDS patients. The majority of respondents perceived medium (28.2\%) to high $(29.1 \%)$ level of stigmatization of PLHIV by health workers. Overall the level of confidence of the respondents on care of PLHIV was moderate.

\section{Discussion}

Nursing and midwifery students during their training program are expected to acquire knowledge, skills, and experience during classroom instruction and clinical practice. When students lack knowledge, they easily demonstrate fear, stigmatization and unwillingness to care for PLHIV which is very harmful to their practice as they are expected to resume their nursing role as primary care providers [8]. Overall the HIV/AIDS knowledge of the respondents in this study was moderate. The finding of moderate level of HIV/AIDS knowledge in this study is in line with studies performed elsewhere [18] [19]. The level of HIV/ AIDS knowledge in this study is however lower compared to that of nursing students in Japan [20] and India [21] in which HIV/AIDS knowledge was observed to be very high. Japan and India are more advance in science and technology compared to Cameroon and this may have accounted for the differences observed. The non-availability of a comprehensive training curriculum on health facility, home and community based care and management of HIV and AIDS in nursing schools in Cameroon may also be a factor accounting for the lower level

Table 6. Practice of the 227 respondents towards care of PLHIV.

\begin{tabular}{|c|c|c|c|c|c|}
\hline \multirow{2}{*}{ Respondents practices } & \multicolumn{5}{|c|}{ Scale of responses: frequencies, $n(\%)$} \\
\hline & None/Not at all & Low & Medium & High & Very high \\
\hline How comfortable are you to change HIV/AIDS patients' medication? & $112(49.3)$ & $20(8.8)$ & $46(20.3)$ & $37(16.3)$ & $12(5.3)$ \\
\hline How comfortable are you to change HIV/AIDS patient's dose? & $110(48.5)$ & $25(11.0)$ & $45(19.8)$ & $37(16.3)$ & $10(4.4)$ \\
\hline How confident are you providing counselling to HIV/AIDS patients? & $31(13.7)$ & $16(7.1)$ & $40(17.6)$ & $69(30.4)$ & $71(31.3)$ \\
\hline $\begin{array}{l}\text { To what extent are you cautious not to get infected when taking } \\
\text { care of HIV/AIDS patients? }\end{array}$ & $16(7.1)$ & $11(4.9)$ & $25(11.0)$ & $64(28.1)$ & $111(48.9)$ \\
\hline To what extent do health workers stigmatize HIV/AIDS patients? & $10(4.4)$ & $39(17.2)$ & $64(28.2)$ & $66(29.1)$ & $48(21.2)$ \\
\hline
\end{tabular}


of HIV/AIDS knowledge in the current study. Furthermore, respondents scored their HIV/AIDS knowledge as "Medium" to "High" with only a few scoring "Very high" on a 5-point Likert scale, findings similar to a study performed in China [22]. Knowledge on HIV/AIDS in the current study was not observed to be associated with the age of the respondents, the institution, the level of study, gender or the specialisation of the student.

The positive attitude towards PLHIV, the misconception, prejudice about PLHIV and stigmatization, and opinions on a possible cure of HIV infection are similar to studies performed elsewhere [18] [21]. HIV/AIDS is one of the most common stigmatized health condition in every part of the world especially in resource poor nation where the patients usually present late to the hospital with full blown disease [23]. Nfusi and Steyn [24] posit that stigmatization of any form is the greatest setback for HIV/AIDS treatment and control. Medical students who are supposed to prevent stigmatization of all forms are equally a part of it. This actually defeats all control efforts. Furthermore, the majority of the respondents perceived medium to high level of stigmatization of PLHIV by healthcare providers in this study. Fear of HIV infection was the major reason advanced by the respondents for not willing to work on PLHIV. These findings are similar to studies performed elsewhere [25] [26]. Motivation factors to work on PLHIV included training on HIV counseling, training on management of PLHIV, further training, adequate equipment, and higher wages as indicated by a few respondents. While higher wages should not be a motivation factor, it is also a genuine concern because health workers in many countries especially in the tropics (where state budget for healthcare are usually small) are not well paid and this affects productivity. Bataganya et al. [27] argue that any good healthcare provider should render his/her services as the job demands, not because of increase salaries. The observation that only a few of the respondents supported that PLHIV should be isolated, is similar to that reported by Onasonga et al. [26], but contrary to the study by Abolfotouh et al. [18] in which a majority of the respondents were observed to favour isolation of PLHIV. The fact that only a few respondents in the current study were in favour of isolation of PLHIV is commendable and such mentality sure improves efforts to curb stigmatization. The majority of the respondents were optimistic about the cure of HIV in the current study. While these respondents are optimistic about the cure for HIV/ AIDS, the disease will still be life threatening for a long time [26] [28]. In our study, good HIV/AIDS knowledge was observed to be the only predictor of positive attitude towards PLHIV, which corroborate the study performed by Maswanya et al. [20]. However, the results contradict the study by Abolfotouh et al. [18] in which no association was observed between knowledge and attitude towards PLHIV. These discrepancies could be attributed to the differences in the study design: our study targeted nursing and midwifery students who have never had any form of graduate study (secondary school graduates) meanwhile that of Abolfotouh et al. [18] targeted both secondary school graduates and holders of a Bachelor of Science degree. However HIV/AIDS knowledge and attitude among 
secondary school graduates in the study by Abolfotouh et al. [18] was similar to ours. Our findings suggest that a more appropriate education on HIV will be needed to improve on the attitude of nursing and midwifery students towards PLHIV in the study area.

In the current study, a vast majority of the respondents had once been intern in a medical facility that receives PLHIV. Among them, only about a quarter had used the WHO guidelines for classifying HIV/AIDS patients. Perhaps this explains why most of the respondents did not know the correct meaning of HIV/AIDS. This could also be the reason why most of them had some wrong opinion about some knowledge and attitude about PLHIV. Almost half of the respondents were uncomfortable in changing the treatment or dose of patients meanwhile a vast majority of them were confident in counseling PLHIV. This could be attributed to the lack of adequate knowledge on HIV among the respondents. Durkin [8] posit that when students lack knowledge, they easily demonstrate fear, stigmatization and unwillingness to care for patients with HIV/AIDS, which is very harmful to their practice. The observation that a majority of the respondents had read extra literature on HIV/AIDS in this study is indicative that the students were willing to know much more than their current curriculum could offer. This therefore underscore the need to revise the study curricula of nursing and midwifery institutions in Fako to address this health care issue. Education remains the most important tool in the absence of a cure for HIV/AIDS and remains the most effective means for combating the enormously dreadful disease. Hence emphasis should be laid on HIV education at all levels on the basis of the fact that it is preventable, manageable and controllable, all of which can be realized through education [29].

\section{Conclusion}

The current study demonstrates that nursing and midwifery students have moderate knowledge on HIV/AIDS. There are however considerable misconception and negative attitude towards PLHIV including stigmatization, unwillingness to work on PLHIV, unwillingness to share the same room with someone infected with HIV, and isolation of PLHIV. Good knowledge on HIV/AIDS was observed to be the only predictor of positive attitude towards PLHIV. The overall level of confidence towards care of PLHIV among nursing and midwifery students in Fako was moderate at best. This highlights the need of a more appropriate education of these students to reduce the discrepancies between general knowledge, desirable attitude and care of PLHIV in Fako division of Cameroon.

\section{Limitation}

Although the current study have revealed the gaps that exists in the knowledge, attitude and practice regarding care of PLHIV among nursing and midwifery students in Fako, it is however limited in that it is confined only to nursing and midwifery institutions in Fako division of the South West region. Furthermore, a majority of the students are from the English speaking regions of Cameroon (i.e. 
the North West and the South West). These findings may not be generalizable to the entire population of nursing and midwifery students in Cameroon. Larger studies designed to include students from nursing and midwifery institutions in the other regions of Cameroon will therefore be required to shed more light.

\section{Acknowledgements}

The authors wish to thank the administration of the different government accredited training institutions for allowing us to use their students. The authors are also thankful to the nursing and midwifery students who voluntarily took part in this study.

\section{Authors' Contributions}

D.M.W.I. conceived the study, participated in its design and coordination, data collection, conducted literature search and review, and wrote the first draft. P.F.N. conceived the study, participated in its design and coordination, critically revise the manuscript. E.Y. participated in the design of the study, data collection, and critically revise the manuscript. E.T.K. participated in the statistical analysis, conducted literature search and review, and wrote the first draft. E.K.T. participated in the design and coordination of the study, conducted the literature search and review, and critically revise the manuscript. D.T.A. participated in data collection, statistical analysis, and critically revise the manuscript. K.E.D. participated in the design and coordination of the study, conducted the literature search and critically revise the manuscript. All authors read and approved the final manuscript.

\section{References}

[1] UNAIDS (2016) Global AIDS Update 2016. http://www.unaids.org/sites/default/files/media_asset/global-AIDS-update-2016_en .pdf

[2] UNAIDS (2012) Global Report: UNAIDS Report on the Global AIDS Epidemic 2012. Geneva, Switzerland.

http://www.unaids.org/en/media/unaids/contentassets/documents/epidemiology/20 12/gr2012/20121120_UNAIDS_Global_Report_2012_with_annexes_en.pdf

[3] UNAIDS/WHO (2004) Cameroon: Epidemiological Fact Sheet on HIV/AIDS and Sexually Transmitted Infections-2004 Update. Geneva, Switzerland. http://data.unaids.org/publications/fact-sheets01/cameroon_en.pdf

[4] Kwenti, T.E., Nsagha, D.S., Kwenti, B.D.T. and Njunda, A.L. (2014) Sexual Risk Behaviours among People Living with HIV and Implications for Control in the North West Region of Cameroon. World Journal of AIDS, 4, 198-205. https://doi.org/10.4236/wja.2014.42025

[5] National AIDS Control Committee (2010) The Impact of HIV and AIDS in Cameroon through 2020

http://www.healthpolicyinitiative.com/Publications/Documents/1250_1_Cameroon EN_Singles_Reduced_acc.pdf

[6] Training Manual for test and treat for Prevention of Mother to Child Transmission of HIV (option B+), Cameroon. 2013. 
[7] World Health Organization (2007) Task Shifting: Rational Redistribution of Tasks among Health Workforce Teams: Global Recommendations and Guidelines. Geneva, Switzerland. http://apps.who.int/iris/bitstream/10665/43821/1/9789241596312_eng.pdf

[8] Durkin, A. (2004) Comfort Levels of Nursing Students Regarding Clinical Assignment to a Patient with AIDS. Nursing Education Perspectives, 25, 22-25.

[9] Chen, R., Heisler, M., Amowitz, L., Moreland, R., Mafeni, J.O., Anyamele, C. and Iacopino V. (2005) Discriminatory Attitudes and Practices by Health Workers toward Patients with HIV/AIDS in Nigeria. PLOS Medicine, 2, e246. https://doi.org/10.1371/journal.pmed.0020246

[10] Ajobiewe, O. and Uwakwe, C. (1998) An Evaluative Assessment of the HIV/AIDS Related Knowledge, Attitudinal Disposition and Preventive Behaviour of Trainee Nursing and Midwifery in a Nigerian School of Nursing. Monograph University of Ibadan, Ibadan.

[11] Walusimbi, M. and Okonsky, J.G. (2004) Knowledge and Attitude of Nurses Caring for Patients with HIV/AIDS Nursing in Uganda. Applied Nursing Research, 17, 92-93. https://doi.org/10.1016/j.apnr.2004.02.005

[12] Atulomah, N. and Oladepo, O. (2002) Knowledge, Perception and Practice with Regards to Occupational Risks of HIV/AIDS among Nursing and Midwifery Students in Ibadan, Nigeria. African Journal of Medicine and Medical Sciences, 31, 223-227.

[13] Österling, A. (1995) Alkoholochattityder. In: Berglund, I.M. and Rydberg, U., Eds., Beroendelära, Studentlitteratur, Lund, 47-52.

[14] Mahat, G. and Eller, L.S. (2009) HIV/AIDS and Universal Precautions: Knowledge and Attitude of Lebanese Nursing Students. Journal of Advanced Nursing, 65, 1907-1915. https://doi.org/10.1111/j.1365-2648.2009.05070.x

[15] Shevel, L., Meriki, H.D., Cho-Ngwa, F. and Fuller, C. (2015) Epidemiology of Human Immunodeficiency Virus-1 and Hepatitis B Virus Co-Infection and Risk Factors for Acquiring These Infections in the Fako Division of Southwest Cameroon. BMC Public Health, 15, 1066. https://doi.org/10.1186/s12889-015-2386-x

[16] Raosoft Sample Size Calculator. www.raosoft.com/samplesize.html

[17] Owaish, A. and Rashed A. (1995) Knowledge, Attitudes, Beliefs and Practices of the Population in Kuwait about AIDS-A Pilot Study. Eastern Mediterranean Health Journal, 1, 235-240.

[18] Abolfotouh, M.A., Al Saleh, S.A., Mahfouz, A.A., Abolfotouh, S.M. and Al Fozan, H.M. (2013) Attitudes of Saudi Nursing Students on AIDS and Predictors of Willingness to Provide Care for Patients in Central Saudi Arabia. SAGE Open, 3, 1-11. https://doi.org/10.1177/2158244013499163

[19] Al-Rabeei, N.A., Dallak, A.M. and Al-Awadi, F.G. (2012) Knowledge, Attitude and Beliefs towards HIV/AIDS among Students of Health Institutes in Sana'a City. Eastern Mediterranean Health Journal, 18, 221-226.

[20] Maswanya, E., Moji, K., Aoyagi, K., Yahata, Y., Kusano, Y., Nagata, K., Izumi, T. and Takemoto, T. (2000) Knowledge and Attitude toward AIDS among Female College Students in Nagasaki, Japan. Health Education Research, 15, 5-11. https://doi.org/10.1093/her/15.1.5

[21] Dharmalingam, M., Poreddi, V., Gandhi, S. and Chandra, R. (2015) Under Graduate Nursing Students' Knowledge and Attitude toward People Living with Human Immunodeficiency Virus/Acquired Immunodeficiency Syndrome. International Journal of Advanced Medical and Health Research, 2, 22-27. 
https://doi.org/10.4103/2349-4220.159124

[22] Tian, X., Pan, J., Zhou, D., Wang, C. and Xie, C. (2007) HIV/AIDS Knowledge, Attitudes and Behaviors Assessment of Chinese Students: A Questionnaire Study. International Journal of Environmental Research and Public Health, 4, 248-253. https://doi.org/10.3390/ijerph2007030009

[23] Phelan, J.C, Link, B.G and Meyer, J.F. (2008) Stigma and Prejudice: One Animal or Two? Social Science and Medicine, 67, 358-367. https://doi.org/10.1016/j.socscimed.2008.03.022

[24] Mfusi, B.J and Steyn, G.M. (2012) Problems in Managing Education Wish HIV/ AIDS Is South Africa. Journal of Human Ecology, 40, 157-166.

[25] Katibi, A.H. and Adeggoke, A.A. (2011) Corrolates of HIV/AIDS Knowledge and Update of HIV Counseling and Testing among Youths in Nigerian Institutions of Higher Learning. Nigerian Journal of Clinical Sciences, 15, 25-38.

[26] Onasoga, O.A., Azetri, P.B. and Atubo, G.F.E. (2014) Clinical Students' Perception toward the Care of HIV Positive Patients in Tertairy Hospotals, Bayelsa State, Nigeria. Journal of Nursing and Health Science, 3, 7-12.

https://doi.org/10.9790/1959-03640712

[27] Bataganya, M., Abdulwadud, O.A. and Kieno, S.M. (2007) Home Bases HIV Voluntary Counseling and Testing in Developing Countries. Cochrane Database of System Review, CD006493.

[28] Ike, S.O. and Aniebue, P.N. (2007) HIV/AIDS Perception and Sexual Behaviour among Nigerian University Students. Nigerian Journal of Clinical Practice, 10, 105-110.

[29] Zhang, Y., Guo, H. and Sun, G. (2010) Relationship between HIV/AIDS Knowledge and Attitude among Student Nurses: A Structural Equation Model. AIDS Patient Care and STDs, 24, 59-63. https://doi.org/10.1089/apc.2009.0190

\section{List of Abbreviations}

PLHIV: People living with HIV/AIDS

HIV: Human Immunodeficiency Virus

AIDS: Acquired Immune Deficiency Syndrome

cOR: crude odd ratio

aOR: adjusted odd ratio

HIAMS: Higher Institute of Applied Medical Sciences

SRNS: State Registered Nursing School 
Submit or recommend next manuscript to SCIRP and we will provide best service for you:

Accepting pre-submission inquiries through Email, Facebook, LinkedIn, Twitter, etc. A wide selection of journals (inclusive of 9 subjects, more than 200 journals)

Providing 24-hour high-quality service

User-friendly online submission system

Fair and swift peer-review system

Efficient typesetting and proofreading procedure

Display of the result of downloads and visits, as well as the number of cited articles Maximum dissemination of your research work

Submit your manuscript at: http://papersubmission.scirp.org/

Or contact wja@scirp.org 